\title{
Comparative Evaluation of Cocoa Bean Husk, Ginger and Chlorhexidine Mouth Washes in the Reduction of Steptococcus Mutans and Lactobacillus Count in Saliva: A Randomized Controlled Trial
}

\author{
Shrimathi S ${ }^{1}$, Umesh Kemparaj ${ }^{1}$, Sangeeta Umesh ${ }^{1}$, Muthu Karuppaiah ${ }^{1}$, Palanivel Pandian ${ }^{1}$, \\ Krishnaveni A ${ }^{2}$ \\ 1. Public Health Dentistry, Best Dental Science College and Hospital, Madurai, IND 2. Pharmacognosy, College of \\ Pharmacy, Madurai Medical College, Madurai, IND
}

Corresponding author: Umesh Kemparaj, drumeshk@gmail.com

\begin{abstract}
Introduction

Dental caries is a ubiquitous bacterial infection that has afflicted people for years. Streptococci mutans ( $S$. mutans) are markers of dental caries and the population of $S$. mutans in the saliva is directly related to the number of surfaces colonized by them. Any intervention that can inhibit their growth and survival will negatively impact the initiation and progress of caries. Various antimicrobial agents have been tested against these microorganisms. The goal of this study was to assess the efficacy of cocoa bean husk, ginger, and chlorhexidine mouth rinse on S. mutans and Lactobacillus.
\end{abstract}

\section{Materials and methods}

We conducted a randomized controlled trial involving patients aged 18 to 25 years from July to September 2018. The study population was allocated into three groups. Each group received either cocoa bean, ginger, or chlorhexidine mouth rinses. The study followed a Latin square design. Study participants were instructed to use the assigned mouth rinse once daily for seven days. We collected saliva samples to measure $S$. mutans and Lactobacillus populations.

\section{Results}

Cocoa bean husk and chlorhexidine rinses produced a significant reduction of $S$. mutans $(\mathrm{p}<0.05)$. The ginger-based rinse significantly reduced the Lactobacillus population $(\mathrm{p}<0.05)$.

Received 06/03/2019 Review began 06/09/2019 Review ended 06/11/2019 Published 06/21/2019

\section{๑) Copyright 2019}

$S$ et al. This is an open access article distributed under the terms of the Creative Commons Attribution License CC-BY 3.0., which permits unrestricted use, distribution, and reproduction in any medium, provided the original author and source are credited.

\section{Conclusion}

Our findings indicate these natural mouth rinses offer promising anticariogenic and antiplaque efficacy as cost-effective alternatives to traditional mouth rinses.

Categories: Public Health, Environmental Health, Other

Keywords: ginger, cocoa bean husk, chlorhexidine, s.mutans, lactobacillus, mouth rinse

\section{Introduction}

Oral health is a reflection of one's general health. Among oral diseases, dental caries is the most common microbial infection and remains a clinical challenge. The main cause of dental caries is attributed to dental plaque [1]. The oral flora consists of 350 cultivable species [2]. The imbalance between preventive measures and increased prevalence of the disease has resulted in an enormous burden on society.

Dental caries is an irreversible disease which affects the tooth structure. Reducing Streptococci load in the oral cavity is a practical step to lower the incidence of dental caries [3]. Many plaque control agents possess promising antimicrobial action.

Mouthwashes used in dentistry for preventative and therapeutic purposes act by chemomechanical action; Chlorhexidine is the most potent chemotherapeutic agent and is the gold standard in reducing $S$. mutans and plaque. Adverse effects are associated with chlorhexidine, which led to a focus on potential natural alternatives with high antibacterial effects but less toxicity than chlorohexidine [2]. Some potential herbal products were used in India for the treatment of various ailments, and recent commercial use of these products in toothpaste and oral irrigation delivery has increased [4]. Examples of potential natural alternatives to chlorohexidine are cocoa bean and ginger. Cocoa bean (Theobroma cacao), the raw ingredient 
of chocolate, belongs to the Malvaceae family has an antibacterial activity [5]. The main substance of polyphenols found in cocoa bean husk is catechin and epicatechin. In addition to these, there are free fatty acids such as oleic acid and linoleic acid that showed strong bactericidal activity against mutans streptococci [6]. Ginger (Zingiber officinale) is native to south-eastern Asia and belongs to the Zingiberaceae family [7]. While ginger is used primarily as a condiment, it seems to be effective against many oral diseases. The main active ingredients of ginger are phenolic compounds (i.e., gingerol and shogaol), sesquiterpene hydrocarbons, and oleoresins [8].

We conducted this study to assess safe and cost-effective mouthwashes for the prevention of oral diseases. Few studies have been conducted that compare the antimicrobial efficacy of chlorhexidine, cocoa bean husk, and ginger. Therefore, our goal was to compare the antimicrobial effects of Chlorhexidine, cocoa bean husk, and ginger mouth rinse on $S$. mutans and Lactobacillus levels in the saliva.

\section{Materials And Methods}

We conducted a double-blinded, randomized controlled crossover study (Latin square design) to compare the effectiveness of ginger, cocoa bean husk, and chlorhexidine mouth rinse on $S$. mutans and Lactobacillus levels in saliva. Ethical approval was obtained from the Institutional review board of Best Dental Science College, Madurai. Study participants were selected from the student body of the Dental College.

Based on previous study data the mean difference of $S$. mutans reduction in the study and control groups was anticipated as 0.45 [5]. Fixing the confidence interval and power of the study to $95 \%$ the sample size was calculated as 23 participants per group. Considering possible attrition of approximate $10 \%$, two subjects were added in each group. The final sample was calculated as 25 subjects per group. The participants were students aged 18 to 25 years who were healthy and provided consent for inclusion. We excluded students who had received antibiotic therapy three weeks before the start of the study, had used a topical fluoride application, or mouthwash 48 hours prior to the study. Also excluded were any students with systemic illness, mental illness, or physical limitations and those with a history of allergy to any of the mouth rinse components used in the study.

Students who met the inclusion criteria were randomized into one of three groups through lottery method, receiving either a $12.5 \%$ ginger rinse (Group A, GING), a $0.2 \%$ chlorhexidine rinse (Group B, CHX), or a $0.5 \%$ cocoa bean husk rinse (Group C, COCOA) respectively.

\section{Preparation of the mouth rinses}

The cocoa bean husk (The Campco, Ltd., Karnataka) and ginger (from a local market) products were washed, dried for one week, and ground to a fine powder.

The extract was obtained using a Soxhlet apparatus. We used $10 \mathrm{~g}$ of powder (either ginger or cocoa bean husk) and $100 \mathrm{ml}$ of $70 \%$ ethanol a solvent. We obtained the extracts by evaporating the solvent via a rotary evaporator maintained at $80^{\circ} \mathrm{C}$ for eight hours. We diluted $50 \mathrm{ml}$ of cocoa bean husk extract and $125 \mathrm{ml}$ of ginger extract in $100 \mathrm{ml}$ of sterile distilled water. We added $0.1 \%$ peppermint oil added as a flavoring and saccharine as sweetening agent to obtain the desired concentration. The mouth rinses were prepared by the Pharmacognosy Department at the Government Pharmacy College in Madurai.

Distribution of the mouth rinse

The study was conducted in three phases and monitored by the principal investigator. The three groups received different mouth rinses packed in $100 \mathrm{ml}$ opaque bottles marked with unique codes for data masking/study blinding. Participants were instructed to use the mouth rinse (10 ml) once per day for seven days in different phases with a washout period of 15 days, according to the Latin square design (Figure 1).

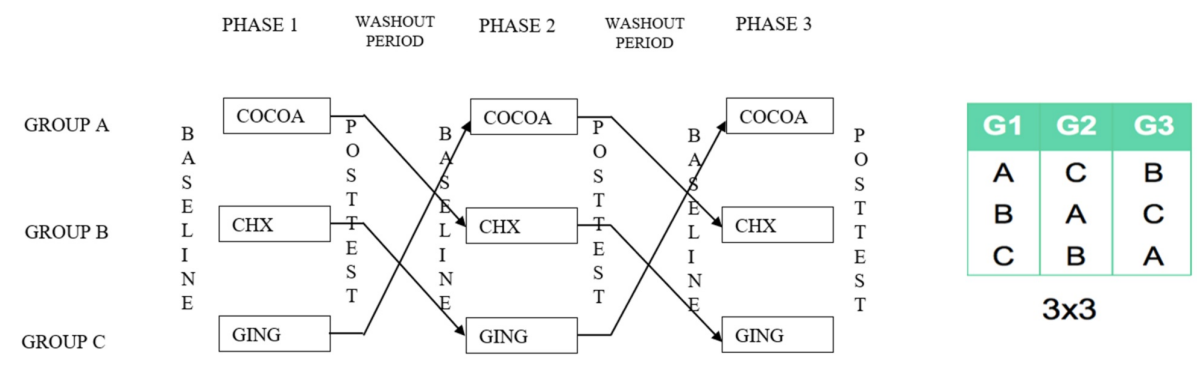

FIGURE 1: Latin square design depicting the sequelae of phases 


\section{Cureus}

Before each phase, participants' unstimulated saliva samples were collected in sterile containers and transferred to the laboratory for microbiological analysis. The collected samples were also masked to group information and stored in a cold storage box and analyzed within one hour of collection. Microbiological analysis was performed at the Department of Microbiology in the American College in Madurai. At the end of each phase, we determined the mean colony forming units (CFUs).

Statistical analysis

We used IBM SPSS Statistics for Windows, Version 22.0 (IBM Corp., Armonk, NY) to analyze the data. We performed an analysis of variance followed by post hoc analysis. We used paired and unpaired t-tests to determine significance. P-values of $<0.05$ were considered statistically significant.

\section{Results}

A total of 75 students were included in the study (32 men and 43 women). We noted statistically significant reductions of $S$. mutans populations in all the three phases. The group of students using chlorhexidine solution had a greater reduction in $S$. mutans counts throughout the study than students using cocoa bean and ginger rinses $(\mathrm{p}<0.05$; Table 1$)$. The mean scores of colony-forming units (CFUs) recorded at the end of each phase of the intervention was consistently lower in cocoa bean husk, ginger, and chlorhexidine group.

\begin{tabular}{|c|c|c|c|c|c|c|c|c|c|c|}
\hline \multirow{2}{*}{ Group } & \multirow{2}{*}{ Variables } & \multicolumn{3}{|l|}{$1^{\text {st }}$ Phase } & \multicolumn{3}{|l|}{$2^{\text {nd }}$ Phase } & \multicolumn{3}{|l|}{$3^{\text {rd }}$ Phase } \\
\hline & & $\begin{array}{l}\text { Mean } \\
\text { (CFUs/uL) }\end{array}$ & SD & $\begin{array}{l}\text { Sig. (two- } \\
\text { tailed) }\end{array}$ & $\begin{array}{l}\text { Mean } \\
\text { (CFUs/uL) }\end{array}$ & SD & $\begin{array}{l}\text { Sig. (two- } \\
\text { tailed) }\end{array}$ & $\begin{array}{l}\text { Mean } \\
\text { (CFUs/uL) }\end{array}$ & SD & $\begin{array}{l}\text { Sig. (two- } \\
\text { tailed) }\end{array}$ \\
\hline \multirow{2}{*}{$\begin{array}{l}\text { Cocoa Bean } \\
\text { Husk }\end{array}$} & Baseline & 2.108 & .952 & \multirow{2}{*}{.032} & 1.644 & 1.652 & \multirow{2}{*}{.021} & 2.444 & 1.781 & \multirow{2}{*}{.023} \\
\hline & Final & 1.610 & .792 & & .909 & .730 & & 1.812 & 1.477 & \\
\hline \multirow{2}{*}{ Chlorhexidine } & Baseline & 2.473 & .812 & \multirow{2}{*}{.001} & 2.004 & 1.074 & \multirow{2}{*}{.014} & 1.672 & .683 & \multirow{2}{*}{.013} \\
\hline & Final & 1.904 & .547 & & 1.372 & .771 & & 1.138 & .757 & \\
\hline \multirow{2}{*}{ Ginger } & Baseline & 2.676 & .980 & \multirow{2}{*}{.040} & 1.161 & .845 & \multirow{2}{*}{.044} & 1.589 & 1.002 & \multirow{2}{*}{.048} \\
\hline & Final & 2.108 & 692 & & .832 & .734 & & 1.274 & .887 & \\
\hline \multicolumn{2}{|c|}{ Inter group p-value } & \multicolumn{2}{|l|}{0.041} & & \multicolumn{2}{|l|}{0.004} & & \multicolumn{2}{|l|}{0.043} & \\
\hline
\end{tabular}

TABLE 1: Inter- and intra-group comparison of Streptococcus mutans values between the three groups at all three phases of intervention

Colony-forming units per microlitre (CFUs/uL).

Lactobacillus count was significantly reduced in the chlorhexidine and ginger groups but was only slightly reduced in the cocoa bean husk-derived rinse group (Table 2). 


\section{Cureus}

\begin{tabular}{|c|c|c|c|c|c|c|c|c|c|c|}
\hline \multirow{2}{*}{ Group } & \multirow{2}{*}{ Variables } & \multicolumn{3}{|l|}{$1^{\text {st }}$ Phase } & \multicolumn{3}{|l|}{$2^{\text {nd }}$ Phase } & \multicolumn{3}{|l|}{$3^{\text {rd }}$ Phase } \\
\hline & & $\begin{array}{l}\text { Mean } \\
\text { (CFUs/uL) }\end{array}$ & SD & $\begin{array}{l}\text { Sig. (2- } \\
\text { tailed) }\end{array}$ & $\begin{array}{l}\text { Mean } \\
\text { (CFUs/uL) }\end{array}$ & SD & $\begin{array}{l}\text { Sig. (2- } \\
\text { tailed) }\end{array}$ & $\begin{array}{l}\text { Mean } \\
\text { (CFUs/uL) }\end{array}$ & SD & $\begin{array}{l}\text { Sig (2- } \\
\text { tailed) }\end{array}$ \\
\hline \multirow{2}{*}{$\begin{array}{l}\text { Cocoa bean } \\
\text { husk }\end{array}$} & Baseline & .210 & .671 & \multirow{2}{*}{.247} & .292 & .699 & \multirow{2}{*}{.953 } & .3308 & .77371 & \multirow{2}{*}{922} \\
\hline & Final & .116 & .300 & & .286 & .573 & & .3132 & .48642 & \\
\hline \multirow{2}{*}{ Chlorhexidine } & Baseline & .693 & 1.469 & \multirow{2}{*}{.037} & .269 & .572 & \multirow{2}{*}{. 048} & .6360 & .88292 & \multirow{2}{*}{012} \\
\hline & Final & .0484 & .102 & & .081 & .282 & & .1168 & .30037 & \\
\hline \multirow{2}{*}{ Ginger } & Baseline & .636 & .882 & \multirow{2}{*}{.021} & .454 & .677 & \multirow{2}{*}{.003} & 4544 & .67794 & \multirow{2}{*}{.003} \\
\hline & Final & .313 & .486 & & .001 & .003 & & .0016 & .00374 & \\
\hline \multicolumn{2}{|c|}{ Inter group $\mathrm{p}$ value } & \multicolumn{3}{|l|}{0.019} & \multicolumn{3}{|l|}{0.02} & \multicolumn{2}{|l|}{0.005} & \\
\hline
\end{tabular}

TABLE 2: Inter- and intra-group comparison of Lactobacillus values between the three groups at all three phase of intervention

Colony-forming units per microlitre (CFUs/uL).

The inter-group comparison shows a minor difference in mean $S$. mutans levels between the three groups $(\mathrm{p}=0.54)$. We noted a higher reduction in the cocoa bean husk group (mean, $0.60 \pm 1.25)$ followed by chlorhexidine (mean, $0.52 \pm 1.04$ ), and ginger (mean, $0.40 \pm 0.97$; Table 3).

\begin{tabular}{|c|c|c|c|c|c|}
\hline \multirow{3}{*}{ Group } & \multicolumn{4}{|l|}{ Paired Differences } & \multirow{3}{*}{ Sig. (two-tailed) } \\
\hline & \multirow{2}{*}{ Mean (CFUs/uL) } & \multirow{2}{*}{ SD } & \multicolumn{2}{|l|}{$95 \% \mathrm{Cl}$} & \\
\hline & & & Lower & Upper & \\
\hline Chlorhexidine & .5248 & 1.04010 & .2855 & .7641 & \multirow{3}{*}{.540} \\
\hline Cocoa husk & .6009 & 1.25053 & .2855 & .7641 & \\
\hline Ginger & .4040 & .97460 & .1798 & .6282 & \\
\hline
\end{tabular}

TABLE 3: Inter-group comparison of S. mutans in all three phases of intervention

Colony-forming units per microlitre (CFU-s/uL).

The inter-group comparison shows a significant mean difference in Lactobacillus levels $(\mathrm{p}=0.003)$. The higher reduction was observed in the chlorhexidine group (mean, $0.45 \pm 1.04$ ) followed by the ginger group (mean, $0.40 \pm 0.66$ ), and cocoa husk group (mean, $0.039 \pm 0.64$; Table 4). 


\section{Cureus}

\begin{tabular}{|c|c|c|c|c|c|}
\hline \multirow{3}{*}{ Group } & \multicolumn{4}{|l|}{ Paired Differences } & \multirow{3}{*}{ Sig. (2-tailed) } \\
\hline & \multirow{2}{*}{ Mean (CFUs/uL) } & \multirow{2}{*}{ SD } & \multicolumn{2}{|l|}{$95 \% \mathrm{Cl}$} & \\
\hline & & & Lower & Upper & \\
\hline Chlorhexidine & .4509 & 1.04183 & .2112 & .6906 & \multirow{3}{*}{.003} \\
\hline Cocoa husk & .0395 & .64267 & -.1084 & .1873 & \\
\hline Ginger & .4095 & .66478 & .2565 & .5624 & \\
\hline
\end{tabular}

TABLE 4: Inter-group comparison of Lactobacillus in all three phases of intervention

Colony-forming units per microlitre (CFUs/uL).

\section{Discussion}

Oral health is an integral part of a person's overall health and quality of life. The paramount causative factor for oral diseases is dental plaque. The formation of plaque on the tooth surface occurs via the synthesis of glucan polymers and glucan binding proteins catalyzed by glucosyltransferases [9]. The progression of initial adherence of bacteria and subsequent accumulation by growth and inter-bacterial adherence lead to the coating of the tooth surface with a complex micro-community leading to the destruction of hard enamel tissue [10].

Herbal oral hygiene products may offer similar benefits to traditional oral hygiene products but with the potential for reduced adverse effects [11]. Several plant extracts exhibit promising antimicrobial effects both in in vitro and in vivo [12]. Cocoa bean husk mouth rinse possesses anti-glucosyltransferase and antibacterial activity which is effective in reducing $S$. mutans and plaque. The glucosyltransferases present in cocoa husk extract inhibits the adhesion of the $S$. mutans to saliva-coated hydroxyapatite and reduces the formation of dental plaque [5]. The active ingredients of ginger (gingerol and shogaol) possess antibacterial activity against $S$. mutans and Lactobacillus that could reduce dental caries through the inhibition of glucan synthesis and adherence $[9,13]$.

In our study, a low-concentration chlorhexidine mouth rinse (0.2\%) caused a significant reduction of $S$. mutans population, which aligns with reports by Sari et al. [14] and Babu et al. [15]. However, our finding of a significant reduction of Lactobacillus contrasted with the Sari et al. study, which reported no difference in Lactobacillus levels [14].

Our cocoa bean husk mouth rinse results (significant reduction of Streptococcus mutans) align with the results reported by Srikanth et al. [5], Babu et al. [15], and Mustamin et al. [16], who used 0.1\% cocoa bean husk mouth rinse twice daily in their study design, and we used $0.5 \%$ cocoa bean husk mouth rinse once daily, suggesting that increasing the concentration and decreasing the frequency of rinses can yield similar results. Reducing the frequency of daily mouth rinsing make the patients more comfortable and increases their compliance. The antimicrobial effects of ginger seen in our study align with findings reported by AlDuboni et al. who found that ginger mouth rinse yielded a greater reduction in lactobacilli than S. mutans [17].

Herbal medications have been introduced as an alternative medicine to prevent and treat oral diseases. Widespread use of such products among the population will be beneficial even to the low socioeconomic status patients. These products were cost-effective and have shown to pose minimal side effects [18].

This study is the first of its kind to compare the effect of cocoa bean husk, ginger, and chlorhexidine on $S$. mutans and Lactobacillus. However, our study had several limitations. Our sample size was small, and the washout period was short. The taste and color of the rinses inhibited full masking of the study design. Further studies are needed to evaluate long-term effects and efficacy in a wider range of age groups.

\section{Conclusions}

Mouth rinses derived from ginger and cocoa bean husks were effective in reducing CFUs/uL of $S$. mutans to a degree similar to the current gold standard for oral rinses, chlorhexidine. A rinse derived from ginger was equally efficacious in reducing the CFUs/uL of Lactobacillus. Ginger is a promising anticariogenic and antimicrobial mouth rinse active ingredient and may offer a lower-cost yet safe caries inhibitory agent compared to traditional mouth rinses.

\section{Additional Information}




\section{Disclosures}

Human subjects: Consent was obtained by all participants in this study. Best Dental Science College and Hospital issued approval 2018-STU-BrVII-SSI-17. Approval to conduct the study is being given. Animal subjects: All authors have confirmed that this study did not involve animal subjects or tissue. Conflicts of interest: In compliance with the ICMJE uniform disclosure form, all authors declare the following: Payment/services info: All authors have declared that no financial support was received from any organization for the submitted work. Financial relationships: All authors have declared that they have no financial relationships at present or within the previous three years with any organizations that might have an interest in the submitted work. Other relationships: All authors have declared that there are no other relationships or activities that could appear to have influenced the submitted work.

\section{Acknowledgements}

I would like to acknowledge post graduates Ms. Gauthami, Mr. Santhosh and their team of microbiologists in American College, Madurai who have constantly supported me in the analysis of the microbiological aspect of this study.

\section{References}

1. Marsh PD: Microbiological aspects of the chemical control of plaque and gingivitis . J Dent Res. 1992, 71:1431-8. 10.1177/00220345920710071501

2. Newman MG, Nisengard R: Oral Microbiology and Immunology, 2nd ed. WB Saunders, Philadelphia, USA; 1994.

3. Oztan MD, Kiyan M, Gerceker D: Antimicrobial effect, in vitro, of gutta-percha points containing root canal medications against yeasts and Enterococcus faecalis. Oral Surg Oral Med Oral Pathol Oral Radiol Endod. 2006, 102:410-6. 10.1016/j.tripleo.2005.10.073

4. Shetty PR, Setty SB, Kamat SS, Aldarti AS, Shetty SN: Comparison of the antigingivitis and antiplaque efficacy of the herboral (herbal extract) mouthwash with chlorhexidine and Listerine mouthwashes: a clinical study. Pak Oral Dental J. 2013, 33:76-81.

5. Srikanth RK, Shashikiran ND, Reddy VS: Chocolate mouth rinse: Effect on plaque accumulation and mutans streptococci counts when used by children. J Indian Soc Pedod Prev Dent. 2008, 26:67-70. 10.4103/09704388.41619

6. Dua R, Kochhar G, Garewal R, Khanna A, Thakur A: Comparison of the antimicrobial efficiency of chlorhexidine and cacao bean husk extract mouth rinses in children. IOSR JDMS. 2017, 16:50-53.

7. Bakhru HK: Herbs that Heal: Natural Remedies for Good Health. Orient Paperbacks, New Delhi; 1992.

8. Bode AM, Dong Z: The amazing and mighty ginger. Herbal Medicine: Biomolecular and Clinical Aspects, 2nd ed. Benzie IF, Wachtel-Galor S (ed): Taylor and Francis Group, Boca Raton, FL; 2011. 131-156. 10.1201/b10787

9. Patel RV, Thaker VT, Patel VK: Antimicrobial activity of ginger and honey on isolates of extracted carious teeth during orthodontic treatment. Asian Pac J Trop Biomed. 2011, 1:58-61. 10.1016/S22211691(11)60124-X

10. Prashant GM, Chandu GN, Murulikrishna KS, Shafiulla MD: The effect of mango and neem extract on four organisms causing dental caries: Streptococcus mutans, Streptococcus salivarius, Streptococcus mitis and Streptococcus sanguis: An in vitro study. Indian J Dent Res. 2007, 18:148-151.

11. Chandrasekaran K: Evaluation of a herbal mouthwash $\left(\right.$ Befresh $^{\mathrm{TM}}$ ) vs. chlorhexidine mouthwash (Clohex Plus): a prospective clinical and microbiological study. EC Microbiology. 2017, 7:209-18.

12. Banas JA, Vickerman MM: Glucan-binding proteins of the oral streptococci . Crit Rev Oral Biol Med. 2003, 14:89-9. 10.1177/154411130301400203

13. Hasan S, Danishuddin M, Khan AU: Inhibitory effect of zingiber officinale towards Streptococcus mutans virulence and caries development: in vitro and in vivo studies. BMC Microbiol. 2015, 15:1. Accessed: June 21, 2019: 10.1186/s12866-014-0320-5

14. Sari E, Birinci I: Microbiological evaluation of $0.2 \%$ chlorhexidine gluconate mouth rinse in orthodontic patients. Angle Orthod. 2007, 77:881-4. 10.2319/080506-320.1

15. Venkatesh Babu NS, Vivek DK, Ambika G: Comparative evaluation of chlorhexidine mouthrinse versus cacao bean husk extract mouthrinse as antimicrobial agents in children. Eur Arch Paediatr Dent. 2011, 12:245-9. 10.1007/BF03262816

16. Mustamin AW: The role of cacao extract in reduction of the number of mutans streptococci colonies in the saliva of 12-14 year-old-children. J Indian Soc Pedod Prev Dent. 2016, 34:120-3. 10.4103/0970-4388.180414

17. Al-Duboni G, Osman MT, Al-Naggar R: Antimicrobial activity of aqueous extracts of cinnamon and ginger on two oral pathogens causing dental caries. Res J Pharm Biol Chem Sci. 2013, 4:957-65.

18. Ekor M: The growing use of herbal medicines: issues relating to adverse reactions and challenges in monitoring safety. Front Pharmacol. 2014, 4:177. Accessed: June 21, 2019: 10.3389/fphar.2013.00177 